\title{
Path Selection of China's Medical Reform Based on Empirical Measurement of Asymmetric Information
}

\author{
Xiaoxuan Yang \\ Department of Economics, University of Wisconsin-Madison, Madison, USA \\ Email: xyang424@wisc.edu
}

How to cite this paper: Yang, X.X. (2018) Path Selection of China's Medical Reform Based on Empirical Measurement of Asymmetric Information. Health, 10, 1406-1430.

https://doi.org/10.4236/health.2018.1010109

Received: September 22, 2018

Accepted: October 26, 2018

Published: October 29, 2018

Copyright $\odot 2018$ by author and Scientific Research Publishing Inc. This work is licensed under the Creative Commons Attribution International License (CC BY 4.0).

http://creativecommons.org/licenses/by/4.0/

\section{(c) (i) Open Access}

\begin{abstract}
Based on the micro individual data from China Health and Nutrition Survey (CHNS) database and the development of China's medical and health system reform since the reform and opening-up in 1978, this paper applies a two-tier stochastic frontier model to measure the degree of asymmetric information between physicians and patients in China's medical service market and estimate the impact of bargaining on the final price of health care both holistically and annually. The empirical results show that: 1) The information mastered by physicians and patients have significant but opposing effects on the final medical service price. Physicians hold more information relative to patients and thus have stronger bargaining power. 2) Almost all patients will be forced to accept a medical price higher than the benchmark price by $16.52 \%$ on average by receiving excessive and expensive medical services, despite the differences in bargaining power between physicians and patients are highly heterogeneous. 3) The series of medical reforms in China had different impacts on medical care pricing efficiency. Especially, the early medical reforms could impose a positive impact on the efficiency of the medical market in the initial stage. I further propose that the path choice of China's new round of medical reform should be as follows: It is necessary to insist on government-led efforts to protect the public welfare of medical services, and to introduce market mechanisms to mobilize social resources and improve the efficiency of the medical market. In addition, I point out that the establishment and improvement of the general practitioner system may reduce the degree of information asymmetry between physicians and patients, thus alleviating China's deteriorating physician-patient relationship.
\end{abstract}

\section{Keywords}

Information Asymmetry, Medical Reform, Bargaining Power, 
Two-Tier Stochastic Frontier Model, General Practitioner

\section{Introduction and Literature Review}

In recent years, the contradictions in the field of medical and health care in China have been aggravating day by day [1], which not only affect national health but also bring about a series of social problems such as poverty and tension between physicians and patients. Two kinds of medical reform ideas of "government-led" and "market competition" have been causing widespread controversy in the civil and academic world. The government-led reform idea is that the government mainly organizes most of medical and health institutions and provides low-cost medical and health services to all the people [2] [3]. The idea of market competition reform is that market competition can play an important role in improving the efficiency of medical and healthcare markets and reducing medical expenditures [4] [5]. Later, some scholars also believed that the roles of the government and the market should both be played in medical reform [6] [7]. Previous studies mainly carried out normative analysis from the theoretical level. However, due to the lack of relevant empirical evidence, it is very difficult to make a convincing conclusion as to which kind of medical reform idea will produce the expected effect.

Since the reform and opening-up in 1978, the Chinese government has implemented a series of medical reform measures based on the above two different medical reform ideas. It is particularly urgent and has practical significance for the provision of China's new round of medical reform to test whether these previous reform measures have really improved the efficiency of China's medical market and then to clarify the responsibility of the government and the market in the entire medical reform. Yet, there are many factors that determine the efficiency of the medical market. Therefore, it is difficult to estimate the efficiency of the Chinese medical market directly from the overall perspective. Among the many factors that affect patients' demand for medical services, medical expenses are the most concerned [8] [9] [10] [11] [12]. Patients will also refer to medical expenses when purchasing medical services. Bernard Gauthier and Waly Wane (2011) found that low-income patients chose to bypass the high-quality medical institutions they could not afford, while high-income patients preferred institutions that offered better quality medical services. And the significant difference in the choice of medical services for patients exists in both urban and rural areas [13].

In the highly competitive Chinese medical service market [14], the actual total cost of medical services reached varies greatly [15] [16]. Even if the medical services provided are fairly homogeneous and standard, the same physician may charge different patients different fees, and different physicians may charge different fees for the same patient. The price dispersion cannot be explained en- 
tirely by the differences in the characteristics of physicians and patients and the quality of medical services. Information asymmetry is absolutely one of the most important factors [17] [18] [19] [20]. Previous studies have also shown that the medical services market has a very significant asymmetry of information [21] [22]. The professionalism of medical services makes physicians have the advantage of information asymmetry, which gives them the incentive to induce demand in their own interests (e.g., overprescribing, prescribing expensive drugs or conducting expensive tests, etc.) [23]. Feldstein's (1970) study shows that the asymmetric information advantage can induce moral hazard of healthcare providers-demand inducement, which increases the patient's healthcare expenditures [24]. Rice (1983) found the amount of medical services would increase after the decline in physician service fees [25]. Yip (1998) concluded that based on demand inducement hypothesis, when a physician's job is affected by the income effect, this physician will make up for the decrease in income by increasing the volume of services [26]. Hengpeng Zhu (2007) pointed out that serious asymmetric information in the medical service market, coupled with the physician-patient inconsistent and even conflicting economic interests provide the possibility and space for physicians to implement moral hazard behaviors: physicians will pursue their own economic interests by using information superiority to induce patients to consume too much medical services and medicines regardless of the interests of patients [27]. And incentives that link physicians' salaries to their income from treatment will allow physicians to take full advantage of asymmetric information to induce more medical needs and then increase health expenditures for patients or the health care system [28]. Although the price of medical services in China is not formed spontaneously through the regulation of market supply and demand, but determined by the relevant government departments, and the price of medicines is also limited by the guidance of the government [29] [30], in the environment of asymmetric information, however, the decision-making power of medical services and the control of total medical expenses are still in the hands of physicians [11], and physicians have absolute discretion over the consumption of medical services. Therefore, the information advantage allows physicians to have bargaining power over the patient's final medical expenditures.

Under China's current medical service system, it is reasonable to assume that patients also have some bargaining power. Because, on the one hand, people who need health care services can have different options. Mommaerts (2018) examined the degree of substitution between nursing home residency and coresidence with adult children [31]. And patients can choose other medical services instead of medical treatment, for example, patients can choose to self-medication, or go directly to the pharmacy to buy medicine. Although such alternative therapies currently occur in common diseases such as colds, the scope of alternative therapies will grow with the development of medical technology [32]. On the other hand, the establishment of the medical information disclosure system [33], 
the development of the network and micromedia [34] and the reference to information provided by trusted relatives and friends [35] enable patients to make choices among different medical institutions. The hypothesis that patients acquire some bargaining power by choosing different medical institutions has also been supported by relevant studies [13] [36] [37].

In the United States, health insurance is primarily provided by commercial insurance, so it is uncommon in health care markets for patients to directly negotiate with providers for health care services rendered, particularly if patients have access to health insurance. Insurers typically bargain on behalf of their enrollees. Unlike the United States, China's medical insurance is mainly provided by the government. At present, China's medical insurance can be divided into social medical insurance projects which are compulsory implemented by the government and commercial health insurance projects which are voluntarily purchased by consumers. Insufficient coverage, inadequate protection, incompetent cost control, inefficient operation and unfair security system are the five major problems facing China's medical insurance [38]. Due to the lack of risk-sharing mechanism, and the current medical insurance payment method is mainly the after-the-fact payment paid by the third-party, a large amount of medical expenses also requires personal direct payment. In addition, China's current medical insurance institutions and medical institutions are separated from each other [39], and there is no negotiation mechanism with medical institutions. Therefore, the trend of rising medical service costs has not been effectively suppressed [40] [41]. From 1978 to 2005, personal cash expenditure on health increased from $20.43 \%$ to $52.2 \%$ in total health expenditure [38]. Because of the lack of fairness in self-funded medical care and the weak anti-risk ability, the economic ability of patients directly determines the timeliness and effectiveness of the medical services they receive, so the inequality of people's income is transformed into the inequality of access to medical services.

In summary, the final expenditures of medical services for patients to go to a hospital are determined by the bargaining process between the physician and the patient. The final medical expenditure reflects the bargaining power of both physicians and patients. And the bargaining power reflects the degree of information asymmetry between the two sides. Therefore, from the perspective of the final medical expenditures paid by patients, I measure the surplus extracted by the physician and the patient in the process of determining the final medical expenses, thus verifying the effectiveness of China's medical reform. Obviously, if the reform of the medical service market really works, we should observe that over time, the surplus acquired by physicians should gradually decrease, and the surplus of patients should gradually increase.

Hongyou Lu et al. (2011) and Wei Xu et al. (2013) used a two-tier stochastic frontier model to measure the degree of information asymmetry between physicians and patients in the medical service market in China and its impact on the final price formation of medical services based on the micro-individual data from the China Health and Nutrition Survey (CHNS) database. Their research 
results show that the information held by both physicians and patients has an important impact on the final price of medical services, and physicians have stronger bargaining power than patients. Therefore, on average, the price of medical services reached is $26.61 \%$ higher than the fair benchmark price. In addition, the net surplus between physicians and patients hardly changed with time. Specifically, the price of medical services for each year is roughly higher than the fair benchmark price of about 26\% from 1989 to 2006 . Therefore, they concluded that since the reform and opening-up, China's medical service system reform has not effectively solved the problem of "expensive medical bills and limited access to quality medical services" [18] [19]. I think the conclusions of these two articles are inconsistent with the reality of China's health care reform. Thus, I use the same methodology and similar data from the same database to conduct an overall and annual empirical measure of the degree of asymmetric information between physicians and patients in China's medical service market and the impact of bargaining on the final price of health care.

The contribution of this paper can be summarized into the following four aspects: 1) I estimate the bargaining power of both physicians and patients during the pricing process of medical services both holistically and annually based on China's micro data using the two-tier stochastic frontier approach, and I find that the information mastered by physicians and patients have significant but opposing effects on the final medical service price, and physicians hold more information relative to patients and thus have stronger bargaining power. 2) I find, for the first time, that the change in net surplus between physicians and patients corresponds to each reform, indicating that the series of medical reforms in China had different impacts on medical care pricing efficiency. More specifically, the early wave of reforms could have a positive impact on the efficiency of the medical market at an early stage. 3) I provide empirical support for policy effects of China's medical reform in different periods and further propose for the path selection of China's new round of medical reform. 4) This paper enriches the research literature of information economics and provides a new research idea for the follow-up policy study.

The remainder structure of the paper is organized as follows: Section 2 briefly reviews the development of China's medical and health system reform. Section 3 describes the intuition and structure of the two-tier stochastic frontier estimation procedure. Section 4 introduces the sources of data and the selection of variables, and Section 5 presents the empirical results. Section 6 provides in-depth discussions on the path selection of China's new round of medical reform, while my conclusions are included in Section 7.

\section{An Overview of the Development of China's Medical Reform}

Since the founding of new China in 1949, China's medical reform has undergone three stages. 1) Public medical care stage (1949-1978), at which the government 
dominated the investment and has constructed the overall medical insurance system from urban to rural areas. In general, China's health care decision-making at this stage has achieved fairness and a significant improvement in people's health. Life expectancy per capita rose from a very low level of 35 years before 1949 to 68 years in 1978 [42]. However, as consumers in the public health care system barely bear the medical expenses, the incentive mechanism encourages the demand side to make excessive use of medical resources, and thus the medical expenses are expanding rapidly. Since the establishment of the public health care system in 1952, efforts to remedy system deficiencies have not been interrupted. 2) Market-oriented reform stage (1978-2003), at which the medical reform policy tended to encourage self-financing medical institutions to replace fiscal expenditure in the health sector, due to the large-scale fiscal pressure caused by the previous public health care and labor insurance system. Otherwise, insufficient medical investment before and after 1979 could hamper the operation of medical system. At this stage, the quantity and quality of medical and health services have been greatly improved, and to some extent, the problems of inefficient hospitals and insufficient supply of medical services have been solved. Meanwhile, the burden of government medical expenditure has also been significantly alleviated. According to the statistics of the China Health Statistics Yearbook in 2004, the number of medical institutions in China increased from 180,553 to 282,771 from 1980 to 2003 , and the number of health technicians per 1,000 people increased from 2.85 to 3.42 . Yet, this stage of reform has brought many serious problems. First, the gap in health care services has expanded between urban and rural areas and between different groups in the city. Second, the medical institutions' compensation mechanism based on excessive sales of drugs has led to rapid and unreasonable growth of medical expenditures for patients. As a result, medical reform has gradually deviated from the public welfare track. 3) Public welfare return stage (2003-present), at which reform decision has gradually brought the medical reform back to the public welfare track. And achieving broad coverage and fairness in medical insurance has become the main theme of medical and health reform at this stage. In addition, the dominance of the government in providing public health and basic medical services has been re-established and the government's responsibilities and investments have been further strengthened. However, the SARS incident in 2003 directly exposed the serious problems existing in the public health field. At the same time, people's problem of expensive medical bills and limited access to quality medical services has posed a more serious challenge to the government's medical and healthcare decisions in the new period.

To respond to challenges and accelerate reforms, it is necessary to comprehensively summarize the basic experiences of China's medical and health system reform since 1949, especially since the reform and opening-up in 1978, to guide the medical reform decision in the new period. Therefore, since 1978, China's medical reform can be divided into the following five stages according to differ- 
ent characteristics of main tasks and reform measures in each period. The first stage (1978-1984) is the gestation period of medical reform, which focused mainly on some adjustments in the internal management of medical institutions without involving changes in the system. The second stage (1985-1991) is the official launch of a comprehensive medical reform, which was reflected in the gradual reduction of governments' direct investment and the progressive marketization of medical institutions. As a result, the vitality of China's medical and health institutions has been further enhanced, and the service capabilities and self-development capabilities of medical institutions have been expanded and improved. The third stage (1992-1999) is the exploration of reform in the direction of "marketization of medical institutions". On the one hand, the government has reduced fiscal expenses to the hospital, and on the other, it has allowed hospitals to become self-financing service agencies. Selling expensive medicine to subsidize medical services has become the main support for the development of hospitals, which can greatly compensate for the insufficient income of medical and health institutions. The fourth stage (2000-2004) is the exploration period in which "marketization" is further pushed forward. In 2000, the auction of public health centers in the city of Suqian, in Jiangsu province, which reformed public medical institutions into profit-making hospitals, started the reform of hospital property rights. Then the auction of more than a hundred public hospitals achieved the withdrawal of state-owned assets and the injection of private capital in the healthcare industry. The fifth stage (2005-2007) is the re-examination of various policies and measures of previous health care reforms. In July 2005, the Chinese government realized that the continuous marketization of medical services in the past two decades has gradually diluted the public welfare nature of public medical institutions, and the pursuit of economic interests has spread in the medical sector. In the same year, China's Ministry of Health stated that maintaining the public welfare nature of public medical institutions has been established as the purpose of medical reform in the new period.

\section{A Brief Review of the Two-Tier Stochastic Frontier Model}

The two-tiered stochastic frontier model, which is called in the settings where it is believed that asymmetric information on both sides of the market leads to surpluses which buyers and sellers can both extract, has been successful across a range of applications. Some examples of such technique that can be applied are the investment efficiency of Chinese listed companies [43], the stock market [44] [45], the real estate market [46], the technology market [47], and the timber auction market [48] and so on.

This study closely follows Kumbhakar and Parmeter (2009) in using a two-tier stochastic frontier model to measure market efficiency [49]. However, Kumbhakar and Parmeter (2009) use the model to measure matching efficiency in a typical labor market, in which the decision on the wage level is the result of negotiations between employees and employers, and ultimately the equilibrium wage 
level depends on the bargaining power (mastered information advantage) of employees and employers. The analysis in the introduction of this paper shows that the medical service expenditure that the patient finally pays to the hospital for medical treatment is determined by the bargaining between the physician and the patient. The ultimate equilibrium price (the actual total expenditure of medical services) reflects the bargaining power of both parties (patients and physicians). And the bargaining power reflects the degree of information asymmetry between the two parties. Therefore, the bargaining mechanism between employers and employees (as in Kumbhakar and Parameter, 2009) is transferable to that between physicians and patients, and thus this particular model is suitable for the medical services market. Scholars who also use the two-tier stochastic frontier technique to study the impact of incomplete information in the medical services market include: Gaynor \& Polachek (1994) [50]; Chawla (2002) [51]; Tomini et al. (2012) [52]; Hongyou Lu et al. (2011) [18]; Wei Xu et al. (2013) [19] and Shangao Wang et al. (2017) [20].

Assume that in a typical medical service market, there are numerous providers and demanders of medical services, physicians and patients have certain information, and the final price $P$ of medical services can be determined by the bargaining between physicians and patients. Then the final price of medical services $P$ can be expressed as:

$$
P=\underline{P}+\eta(\bar{P}-\underline{P})
$$

where $\underline{P}$ represents the physician's reservation price, $\bar{P}$ represents the patient's maximum price offer $(\bar{P} \geq \underline{P})$, and $\eta(0 \leq \eta \leq 1)$ is the bargaining power of physicians in the pricing process. $\eta(\bar{P}-\underline{P})$ represents the share of surplus extracted by physicians in the medical service pricing process.

In order to capture not only the impact of physician's bargaining, but also the impact of patient's bargaining, I first denote the benchmark price, which means the expected "fair" medical service price given a vector of characteristics $x$, by $\mu(x)=E(\theta \mid x)$, where $\theta$ is the unknown but actual "fair" medical service price, and $\underline{P} \leq \mu(x) \leq \bar{P}$ is always satisfied. Therefore, $\bar{P}-\mu(x)$ represents the expected surplus that patients extract in the process of reaching a medical service price, $\mu(x)-\underline{P}$ represents the expected surplus extracted by physicians. And which side can "grab" more surplus will depend on the degree of information they possess, and their bargaining power based on it [53]. Accordingly, Equation (1) can be rewritten as:

$$
\begin{aligned}
P & =\mu(x)-\mu(x)+\underline{P}+\eta(\bar{P}-\underline{P}+\mu(x)-\mu(x)) \\
& =\mu(x)+(\underline{P}-\mu(x))+\eta(\bar{P}-\mu(x))-\eta(\underline{P}-\mu(x)) \\
& =\mu(x)+\eta(\bar{P}-\mu(x))-(1-\eta)(\mu(x)-\underline{P})
\end{aligned}
$$

Equation (2) indicates that the final price of health care, in fact, consists of three components: the "fair" price of medical services $\mu(x)$ conditional on a vector of individual characteristics $x$, which I will hereinafter refer to as the 
benchmark price, the share of patient's surplus extracted by the physician, $\eta(\bar{P}-\mu(x)) \geq 0$, and the share of physician's surplus extracted by the patient, $(1-\eta)(\mu(x)-\underline{P}) \geq 0$. From the practical point of view, the net surplus, $N S=\eta(\bar{P}-\mu(x))-(1-\eta)(\mu(x)-\underline{P})$, represents the overall effect of bargaining on medical service price. Thus, the share of extracted surplus depends on the bargaining power of both physicians and patients. Namely, physicians with stronger bargaining power will increase the final price of medical services, conversely, patients with stronger bargaining power will decrease the final medical price. As a result, the impact of bargaining power of both physicians and patients on the final price of medical services is two-sided. Following Kumbhakar and Parmeter (2009), I can further simplify Equation (2) for the ith observation in a two-tier stochastic frontier model format as follows:

$$
P_{i}=x_{i}^{\prime} \beta+\xi_{i}, \text { where } \xi_{i}=w_{i}-u_{i}+v_{i}, i=1, \cdots, n .
$$

where I assume $\mu(x)$ is linear in parameters, namely, $\mu\left(x_{i}\right)=x_{i}^{\prime} \beta \quad\left(x_{i}\right.$ is a vector of covariates that represent observable characteristics that may impact medical price, $\beta$ is the corresponding parameter vector) and let $\xi_{i}$ denote the composite error term enclosing $w_{i}=\eta_{i}\left(\bar{P}_{i}-\mu\left(x_{i}\right)\right) \geq 0$, $u_{i}=\left(1-\eta_{i}\right)\left(\mu\left(x_{i}\right)-\underline{P}_{i}\right) \geq 0$, and $v_{i}$, which is the classical error term. Since $w_{i}$ and $u_{i}$ are one-sided, non-zero $E\left(\xi_{i}\right)$ will cause the biased OLS estimate of the intercept. Additionally, my focus is mainly on disentangling the surplus extraction components $w_{i}$ and $u_{i}$ from the composed error term $\xi_{i}$, rather than estimating the $\beta$ parameters. Thus, I use the maximum likelihood (ML) method to estimate the Model (3) by assuming that $v_{i} \sim$ i.i.d.N $\left(0, \sigma_{v}^{2}\right)$, $w_{i} \sim$ i.i.d. $\operatorname{Exp}\left(\sigma_{w}, \sigma_{w}^{2}\right)$ and $u_{i} \sim$ i.i.d. $\operatorname{Exp}\left(\sigma_{u}, \sigma_{u}^{2}\right)$.

At the same time, I assume that $u_{i}, w_{i}$ and $v_{i}$ are independent of each other and are both independent of individual features $x_{i}$. These distribution assumptions are necessary for empirical analysis, considering that the two-tier frontier model is nonparametrically underidentified. Of course, $w_{i}$ and $u_{i}$ can also be assumed to follow other types of one-sided distribution, such as the half-normal distribution, log-normal distribution, and gamma distribution, etc. Yet, since Kumbhakar and Lovell (2000) showed that using different distributional assumptions would not have a substantial impact on the estimation results [54], I therefore assume exponential distribution due to its simplicity. Based on the above assumptions, the probability density function of $\xi_{i}$ can be derived as follows (for details, see Kumbhakar and Parmeter, 2009 [49]):

$$
f\left(\xi_{i}\right)=\frac{\exp \left(a_{i}\right)}{\sigma_{u}+\sigma_{w}} \Phi\left(c_{i}\right)+\frac{\exp \left(b_{i}\right)}{\sigma_{u}+\sigma_{w}} \int_{-h_{i}}^{\infty} \phi(z) \mathrm{d} z=\frac{\exp \left(a_{i}\right)}{\sigma_{u}+\sigma_{w}} \Phi\left(c_{i}\right)+\frac{\exp \left(b_{i}\right)}{\sigma_{u}+\sigma_{w}} \phi\left(h_{i}\right)
$$

where $\Phi(\cdot)$ and $\phi(\cdot)$ are the cumulative distribution function and the probability density function of standard normal distribution respectively, and $a_{i}=\sigma_{v}^{2} / 2 \sigma_{u}^{2}+\xi_{i} / \sigma_{u}, b_{i}=\sigma_{v}^{2} / 2 \sigma_{w}^{2}-\xi_{i} / \sigma_{w}, h_{i}=\xi_{i} / \sigma_{v}-\sigma_{v} / \sigma_{w}$, $c_{i}=-\xi_{i} / \sigma_{v}-\sigma_{v} / \sigma_{u}$.

Furthermore, for a sample containing $n$ observations, the log-likelihood func- 
tion can be expressed as follows:

$$
\ln L(X, \theta)=-n \ln \left(\sigma_{u}+\sigma_{w}\right)+\sum_{i=1}^{n} \ln \left[\mathrm{e}^{a_{i}} \Phi\left(c_{i}\right)+\mathrm{e}^{b_{i}} \Phi\left(h_{i}\right)\right]
$$

where $\theta=\left[\beta, \sigma_{v}, \sigma_{u}, \sigma_{w}\right]^{\prime}$. By maximizing the log-likelihood function, we can obtain the maximum likelihood estimates of all parameters. It should be noted that since $\sigma_{w}$ and $\sigma_{u}$ appear separately in the likelihood function (i.e., $\sigma_{w}$ only appears in $b_{i}$ and $h_{i}$, and $\sigma_{u}$ only appears in $a_{i}$ and $c_{i}$ ), identification of these two values can be achieved. Thus, another reason for assuming that surpluses extracted by physicians and patients obey exponential distribution is that likelihood functions can be expressed in a closed form, and the identification of variance parameters is obvious.

In this paper, I focus on obtaining the estimates of surpluses extracted by the physician and the patient. For this purpose, I need to further derive the conditional distributions of $u_{i}$ and $w_{i}$, denoted by $f\left(u_{i} \mid \xi_{i}\right)$ and $f\left(w_{i} \mid \xi_{i}\right)$, which are:

$$
f\left(u_{i} \mid \xi_{i}\right)=\frac{\lambda \exp \left(-\lambda u_{i}\right) \Phi\left(u_{i} / \sigma_{v}+h_{i}\right)}{\Phi\left(h_{i}\right)+\exp \left(a_{i}-b_{i}\right) \Phi\left(c_{i}\right)}
$$

and

$$
f\left(w_{i} \mid \xi_{i}\right)=\frac{\lambda \exp \left(-\lambda w_{i}\right) \Phi\left(w_{i} / \sigma_{v}+c_{i}\right)}{\exp \left(b_{i}-a_{i}\right)\left[\Phi\left(h_{i}\right)+\exp \left(a_{i}-b_{i}\right) \Phi\left(c_{i}\right)\right]} .
$$

where $\lambda=1 / \sigma_{u}+1 / \sigma_{w}$. Moreover, I can derive the conditional expectation of $u_{i}$ and $w_{i}$ respectively as:

$$
E\left(u_{i} \mid \xi_{i}\right)=\frac{1}{\lambda}+\frac{\exp \left(a_{i}-b_{i}\right) \sigma_{v}\left[\phi\left(-c_{i}\right)+c_{i} \Phi\left(c_{i}\right)\right]}{\Phi\left(h_{i}\right)+\exp \left(a_{i}-b_{i}\right) \Phi\left(c_{i}\right)} .
$$

and

$$
E\left(w_{i} \mid \xi_{i}\right)=\frac{1}{\lambda}+\frac{\sigma_{v}\left[\phi\left(-h_{i}\right)+h_{i} \Phi\left(h_{i}\right)\right]}{\Phi\left(h_{i}\right)+\exp \left(a_{i}-b_{i}\right) \Phi\left(c_{i}\right)} .
$$

which indicate the percentage deviation of the medical price from the optimal boundary (benchmark price) resulting from the physician-patient bargaining power, when $u$ and $w$ are small, since the dependent variable in this paper is in logarithmic form. In order to obtain the exact percentage deviation between the actual medical price and the benchmark price, Equations (8) and (9) can be interpreted as follows:

$$
E\left(1-\mathrm{e}^{-u_{i}} \mid \xi_{i}\right)=1-\frac{\lambda}{1+\lambda} \frac{\left[\Phi\left(h_{i}\right)+\exp \left(a_{i}-b_{i}\right) \exp \left(\frac{\sigma_{v}^{2}}{2}-\sigma_{v} c_{i}\right) \Phi\left(c_{i}-\sigma_{v}\right)\right]}{\Phi\left(h_{i}\right)+\exp \left(a_{i}-b_{i}\right) \Phi\left(c_{i}\right)} .
$$

and

$$
E\left(1-\mathrm{e}^{-w_{i}} \mid \xi_{i}\right)=1-\frac{\lambda}{1+\lambda} \frac{\left[\Phi\left(c_{i}\right)+\exp \left(b_{i}-a_{i}\right) \exp \left(\frac{\sigma_{v}^{2}}{2}-\sigma_{v} h_{i}\right) \Phi\left(h_{i}-\sigma_{v}\right)\right]}{\exp \left(b_{i}-a_{i}\right)\left[\Phi\left(h_{i}\right)+\exp \left(a_{i}-b_{i}\right) \Phi\left(c_{i}\right)\right]} .
$$


and the net surplus:

$$
N S=E\left(1-\mathrm{e}^{-w_{i}} \mid \xi_{i}\right)-E\left(1-\mathrm{e}^{-u_{i}} \mid \xi_{i}\right)=E\left(\mathrm{e}^{-u_{i}}-\mathrm{e}^{-w_{i}} \mid \xi_{i}\right) .
$$

which describes the net effect of asymmetric information on medical price.

\section{Data and Variable Selection}

\subsection{Data Sources}

The data used in this paper is from the China Health and Nutrition Survey (CHNS) database, which was jointly created by the Carolina Population Center at the University of North Carolina at Chapel Hill and the National Institute for Nutrition and Health at the Chinese Center for Disease Control and Prevention. I select the survey data of six provinces (Heilongjiang, Liaoning, Jiangsu, Shandong, Guizhou and Guangxi) across the north and south regions of China in six years $(1991,1993,1997,2000,2004,2006)$. Because this survey data comes from a large number of questionnaires, its sample size is limited compared to the data of listed companies and macroscale statistics, and it is quite noisy. In order not to interfere too much with the data, I carefully screened the data before using it. I excluded individual samples under 18 years of age whose medical expenses are mainly borne by their parents and are often inelastic, thus it is difficult to truly reflect the price characteristics of the medical service market. Additionally, I removed all samples of medical expenses paid entirely by insurance companies. Then, I erased the missing sample. Finally, I obtained 1208 observations, and their distribution features are shown in Table 1.

Geographically speaking, the distribution of samples in six provinces is roughly balanced, which means the samples are broadly representative. In the meantime, the sample sizes of Liaoning, Jiangsu, Guangxi and Guizhou ranked the top four, indicating that the samples can better reflect the regional differences in economic development level. From the timing point of view, the sample size increases year by year. In addition, the samples are basically balanced in urban-rural distribution and gender distribution.

\subsection{The Selection of Variables}

Since patients may receive very different levels of care, the variation in medical prices could be mostly due to the services patients received, rather than the bargaining power of providers relative to patients. Therefore, ideally, this study would require price data on a specific type of care (e.g., heart bypass surgery). However, there is no relevant data available in the questionnaire. Thus, in the measurement of the price of medical services (the dependent variable in this paper), I select the total expenditure of the medical service reported by the patient (corresponding to the questionnaire question M39 "money spent on illness or injury"), which includes the medical expenses and the drug fee, instead of the unit price of a particular type of medical service. Because patients can indirectly "select" medical expenses by choosing to go to different hospitals, and "select" 
Table 1. Sample distribution.

\begin{tabular}{|c|c|c|c|c|c|c|c|c|}
\hline & \multirow{2}{*}{$\begin{array}{l}\text { Observation } \\
\text { sample }\end{array}$} & \multirow{2}{*}{$\begin{array}{c}\text { Percent } \\
(\%)\end{array}$} & \multicolumn{2}{|c|}{ Urban and rural } & \multicolumn{2}{|c|}{ Gender } & \multicolumn{2}{|c|}{ Medical Insurance } \\
\hline & & & $\begin{array}{c}\text { Rural } \\
(\%)\end{array}$ & $\begin{array}{c}\text { Urban } \\
(\%)\end{array}$ & $\begin{array}{c}\text { Female } \\
(\%)\end{array}$ & $\begin{array}{c}\text { Male } \\
(\%)\end{array}$ & $\begin{array}{l}\text { No } \\
(\%)\end{array}$ & $\begin{array}{l}\text { Yes } \\
(\%)\end{array}$ \\
\hline \multicolumn{9}{|c|}{ Panel A: Survey Year } \\
\hline 1991 & 58 & 4.80 & 3.64 & 1.16 & 3.23 & 1.57 & 3.56 & 1.24 \\
\hline 1993 & 72 & 5.96 & 4.88 & 1.08 & 3.23 & 2.73 & 4.47 & 1.49 \\
\hline 1997 & 142 & 11.75 & 4.88 & 6.87 & 6.04 & 5.71 & 6.95 & 4.80 \\
\hline 2000 & 182 & 15.07 & 9.44 & 5.63 & 8.77 & 6.29 & 11.01 & 4.06 \\
\hline 2004 & 451 & 37.33 & 20.53 & 16.80 & 21.36 & 15.98 & 25.41 & 11.92 \\
\hline 2006 & 303 & 25.08 & 11.01 & 14.07 & 13.91 & 11.18 & 10.60 & 14.49 \\
\hline Total & 1208 & 100 & 54.38 & 45.62 & 56.54 & 43.46 & 62.00 & 38.00 \\
\hline \multicolumn{9}{|c|}{ Panel B: Province } \\
\hline Liaoning & 279 & 23.10 & 11.34 & 11.75 & 13.58 & 9.52 & 13.58 & 9.52 \\
\hline Heilongjiang & 139 & 11.51 & 4.64 & 6.87 & 6.29 & 5.22 & 6.79 & 4.72 \\
\hline Jiangsu & 246 & 20.36 & 11.92 & 8.44 & 11.75 & 8.61 & 7.62 & 12.75 \\
\hline Shandong & 102 & 8.44 & 4.14 & 4.30 & 4.39 & 4.06 & 4.97 & 3.48 \\
\hline Guangxi & 253 & 20.94 & 13.25 & 7.70 & 11.67 & 9.27 & 16.23 & 4.72 \\
\hline Guizhou & 189 & 15.65 & 9.11 & 6.54 & 8.86 & 6.79 & 12.83 & 2.81 \\
\hline Total & 1208 & 100 & 54.38 & 45.62 & 56.54 & 43.46 & 62.00 & 38.00 \\
\hline
\end{tabular}

Note: All percentages in the table are ratios to the total number of samples.

drug prices by deciding whether to buy drugs in the hospital (or to go to a nearby pharmacy), both options make patients have certain bargaining power. Therefore, although the price data is limited by the setting of the questionnaire itself and cannot be subdivided, this indicator can largely measure the price of the patient's consumption of medical services. From the descriptive statistics in Table 2, the distribution of medical expenditures is very discrete, with a maximum of 9000 and a minimum of 1.01. The standard deviation is also very large. So, in the subsequent empirical analysis, I performed a natural logarithmic transformation of this variable to minimize the impact of potential outliers on the regression results.

To measure the "benchmark price" $\mu(x)$ in Model (3), I choose the following individual feature variables: 1 ) Severity of the illness or injury (Symptoms). I originally wanted to use the problem M40 (doctor's diagnosis of illness/injury) in the questionnaire to measure the condition of the disease. But because patients' conditions in the questionnaire were divided into 22 kinds, and they are not easy to merge, and a large number of respondents did not answer for privacy reasons, I eventually abandoned this indicator and used the question M25 (how severe was the illness or injury) to describe the urgency of the patient's consumption. The larger the indicator, the more urgent the consumer behavior is. 2) Expectations of health value (Endurance). Residents have different expectations about their health status and life value, so they have different choices in medical 
Table 2. Statistical description of variables.

\begin{tabular}{|c|c|c|c|c|c|c|c|c|}
\hline Variable & Mean & $\mathrm{Sd}$ & Min & Q1 & Q2 & Q3 & Max & Variable explanation \\
\hline Price & 212.415 & 737.592 & 1.01 & 10 & 30 & 100 & 9000 & Reported total medical service expenditures \\
\hline Age & 53.345 & 15.73 & 13 & 42 & 54 & 66 & 93 & \\
\hline Symptoms & 1.633 & 0.648 & 1 & 1 & 2 & 2 & 3 & $\begin{array}{l}\text { How severe was the illness or injury? } \\
\text { (1: not severe, } 2 \text { : somewhat, } 3 \text { : quite) }\end{array}$ \\
\hline Urban & 0.456 & 0.498 & 0 & 0 & 0 & 1 & 1 & (1: urban, o: rural) \\
\hline Sex & 0.435 & 0.496 & 0 & 0 & 0 & 1 & 1 & (1: male, 0 : female) \\
\hline Married & 0.072 & 0.259 & 0 & 0 & 0 & 0 & 1 & (1: unmarried, $0:$ married (including divorce)) \\
\hline Education & 1.832 & 1.176 & 0 & 1 & 1 & 2 & 5 & Education level \\
\hline Insurance & 0.38 & 0.486 & 0 & 0 & 0 & 1 & 1 & (1: yes, $0:$ no) \\
\hline Job & 0.498 & 0.5 & 0 & 0 & 0 & 1 & 1 & (1: yes, $0:$ no) \\
\hline \multirow[t]{2}{*}{ Endurance } & \multirow[t]{2}{*}{0.683} & \multirow[t]{2}{*}{0.466} & \multirow[t]{2}{*}{0} & \multirow[t]{2}{*}{0} & \multirow[t]{2}{*}{1} & \multirow[t]{2}{*}{1} & \multirow[t]{2}{*}{1} & $\begin{array}{l}\text { Expectations of health value: } \\
\text { Was medical care sought? } \\
\text { (1: self-care, } 0 \text { : saw a doctor) }\end{array}$ \\
\hline & & & & & & & & Control variables \\
\hline Area & - & - & - & - & - & - & - & Survey province \\
\hline Year & - & - & - & - & - & - & - & Survey year \\
\hline
\end{tabular}

Note: Q1, Q2 and Q3 represent the first, second and third quartiles, namely, the 25th, 50th and 75th percentiles, respectively (same as below).

services. M26 (was medical care sought?) in the questionnaire can better describe the impact of this factor. Specifically, residents with higher expectations of health and life value are more likely to choose medical treatment, while residents with lower expectations are more likely to treat themselves or ignore common diseases. 3) Other variables. I also considered factors which may affect the patient's medical service consumption preference, including individual's age, living region, gender, marital status, level of education, stable job, and medical insurance. Finally, I controlled the regional factors of different provinces and the impact of time factors in different survey years. Table 2 shows the definition methods and basic statistics of the above variables.

It should be noted that, considering the impact of income levels on the total expenditure of medical services received by patients, I also attempted to include income variables in the analysis. Nevertheless, the questionnaire only asked for the monthly salary of the respondent who had a stable job (according to question B2), while the monthly income of non-working individuals is zero, so I finally gave up the income indicator. In addition, the individual characteristics of the physicians who provide medical services to patients are not covered in the questionnaire. The only question designed to address the characteristics of the medical institution chosen by the patient is M27b (where did you see a physician?), but because a large number of respondents did not answer this question, I did not eventually adopt it. I will leave the impact of income level and hospital type (scale) on patients' medical preference for future research. 


\section{The Empirical Results}

In this section, instead of determining the marginal effect of covariates, based on the model specification, I conduct variance decomposition analysis of the two-tier stochastic frontier model to not only explore the impact of bargaining power over medical service expenditures but also obtain the holistic and annual estimates of extracted surplus due to different bargaining power between physicians and patients.

\subsection{Model Specification}

Since we can only observe the medical expenses paid by patients, the theoretical fair price $\mu(x)$ is unobservable. And previous studies have no conclusive opinion of what factors must affect the fair medical price. Therefore, I try to add the factors mentioned in the previous literature that may affect the fair price and decide whether to include this influencing factor in the model according to its significant level, to determine the best model specification. Table 3 presents the results of parameter estimations based on the two-tier stochastic frontier model.

In Table 3, Model (1) uses the OLS estimation method, and Models (2) - (7) use the MLE method based on the two-tier stochastic frontier technique. Model (2) only contains the classical error term $V_{i}$ and ignores the effect of bargaining on the final medical expenditures. The error term in Model (3) is $\xi_{i}=w_{i}-u_{i}+v_{i}$. By considering factors such as stable job, medical insurance and expectations of health value, the fitness of Model (4) is significantly improved. Furthermore, in Models (5) - (7), by excluding the insignificant factors (gender and marital status) and further increasing the control of different survey provinces and different survey years, the fitness of models has been greatly improved. The largest log likelihood value and the LR test value of Model (7) indicates that Model (7) is the best specification, so the subsequent analysis in this paper is mainly based on the variables and measurement results under Model (7).

\subsection{Variance Decomposition Analysis: The Effect of Bargaining Power on Medical Service Prices}

Table 4 reports the results of bargaining power effect analysis. I find that bargaining power has a considerable impact on the formation of medical service prices. Specifically, the stronger bargaining power of physicians compared with patients leads to a positive net effect of negotiations over the price of medical services, which can be found from the estimate of $E(w-u)=\sigma_{w}-\sigma_{u}=51.55 \%$. Therefore, in general, bargaining will result in a higher medical price relative to the benchmark price. In addition, the unexplained variation in log price $\left(\sigma_{v}^{2}+\sigma_{u}^{2}+\sigma_{w}^{2}\right)$ is 2.2465 , of which $61.57 \%$ is due to physician-patient bargaining. And bargaining power is determined by information asymmetry [55] [56]. Furthermore, physicians' bargaining power accounts for $79.47 \%$ of the total impact of negotiations on prices and is almost decisive for the price of medical services. Therefore, although patients do have some bargaining power (accounts for 
Table 3. Estimates of log price regression function.

\begin{tabular}{|c|c|c|c|c|c|c|c|}
\hline \multirow{2}{*}{ Variable } & \multicolumn{7}{|c|}{ Lnprice } \\
\hline & Model 1 & Model 2 & Model 3 & Model 4 & Model 5 & Model 6 & Model 7 \\
\hline \multirow[t]{2}{*}{ Lnage } & $1.182^{* * *}$ & $1.214^{\star * *}$ & $1.137^{\star * *}$ & $0.768^{\star * *}$ & $0.801^{* * *}$ & $0.815^{* * *}$ & $0.657^{* * *}$ \\
\hline & $(7.234)$ & (7.542) & $(7.250)$ & (4.494) & (5.625) & (5.843) & $(4.720)$ \\
\hline \multirow[t]{2}{*}{ Symptoms } & $0.881^{\star * *}$ & $0.900^{* * *}$ & $0.861^{\star * *}$ & $0.788^{* * *}$ & $0.788^{* * *}$ & $0.748^{* * *}$ & $0.742^{* * *}$ \\
\hline & $(12.303)$ & $(12.614)$ & $(12.422)$ & (11.776) & (11.777) & (11.378) & $(11.521)$ \\
\hline \multirow[t]{2}{*}{ Urban } & $0.199^{* *}$ & $0.224^{* *}$ & $0.186^{* *}$ & $0.210^{* *}$ & $0.210^{* *}$ & $0.173^{*}$ & 0.144 \\
\hline & $(2.073)$ & $(2.323)$ & (2.009) & $(2.293)$ & $(2.300)$ & (1.933) & $(1.633)$ \\
\hline \multirow[t]{2}{*}{ Sex } & 0.010 & -0.002 & 0.002 & 0.034 & - & - & - \\
\hline & $(0.104)$ & $(-0.026)$ & $(0.022)$ & $(0.382)$ & & & \\
\hline \multirow[t]{2}{*}{ Married } & 0.181 & 0.207 & 0.204 & -0.063 & - & - & - \\
\hline & $(0.864)$ & (1.035) & $(1.030)$ & $(-0.322)$ & & & \\
\hline \multirow[t]{2}{*}{ Education } & $0.128^{* * *}$ & $0.141^{* * *}$ & $0.129^{\star * *}$ & $0.129^{* * *}$ & $0.132^{* * *}$ & $0.119^{* * *}$ & $0.093^{* *}$ \\
\hline & $(3.005)$ & (3.244) & $(3.188)$ & (3.104) & (3.195) & (2.934) & $(2.314)$ \\
\hline \multirow[t]{2}{*}{ Job } & - & - & - & $-0.418^{\star * *}$ & $-0.406^{\star * *}$ & $-0.356^{\star * *}$ & $-0.349^{* * *}$ \\
\hline & & & & $(-4.225)$ & $(-4.281)$ & $(-3.813)$ & $(-3.797)$ \\
\hline \multirow[t]{2}{*}{ Endurance } & - & - & - & $-0.800^{\star * *}$ & $-0.799^{\star * \star}$ & $-0.890^{\star * *}$ & $-1.079^{* * *}$ \\
\hline & & & & $(-8.341)$ & $(-8.344)$ & $(-9.083)$ & $(-10.092)$ \\
\hline \multirow[t]{2}{*}{ Insurance } & - & - & - & $0.216^{\star *}$ & $0.217^{\star *}$ & 0.108 & 0.090 \\
\hline & & & & (2.309) & $(2.322)$ & (1.124) & $(0.935)$ \\
\hline \multirow[t]{2}{*}{ Constance } & $-2.811^{\star * \star}$ & $-3.068^{* * *}$ & $-3.568^{* * *}$ & -0.892 & $-1.021^{*}$ & $-1.182^{\star}$ & $-1.378^{\star \star}$ \\
\hline & $(-4.218)$ & $(-4.687)$ & $(-5.584)$ & $(-1.235)$ & $(-1.691)$ & $(-1.959)$ & $(-2.329)$ \\
\hline Province dummies & - & - & - & - & - & Control & Control \\
\hline Year dummies & - & - & - & - & - & - & Control \\
\hline Adj R-squared & 0.167 & - & - & - & - & - & - \\
\hline Log likelihood & - & -2281.88 & -2263.06 & -2220.86 & -2220.97 & -2192.15 & -2168.79 \\
\hline LR test (chi2) & - & - & 37.635 & 122.032 & 121.811 & 179.454 & 226.165 \\
\hline $\mathrm{P}$-value & - & - & 0.000 & 0.000 & 0.000 & 0.000 & 0.000 \\
\hline $\mathrm{N}$ & 1208 & 1208 & 1208 & 1208 & 1208 & 1208 & 1208 \\
\hline
\end{tabular}

Note: $\mathrm{t}$ statistics are reported in parentheses. ${ }^{\star} \mathrm{P}<0.1,{ }^{* \star} \mathrm{P}<0.05,{ }^{* *} \mathrm{P}<0.01$.

20.53\%), the formation of medical service prices depends more on physicians. To analyze the surplus extracted by physicians and patients and the net surplus in the bargaining process, I further estimate the unilateral effect of both physicians and patients.

\subsection{Unilateral Effect Estimation: Surplus Extracted by Patients and Physicians}

\subsubsection{The Overall Results of the Sample Estimates}

The emphasis of this paper is to estimate the surplus obtained by both patients and physicians $(E(u \mid \xi)$ and $E(w \mid \xi))$ under asymmetric information. The 
Table 4. The effect of bargaining power on medical prices.

\begin{tabular}{cccc}
\hline & Variable meaning & Variable expression & Estimate \\
\hline \multirow{2}{*}{ Negotiation mechanism } & Random error term & $\sigma_{v}$ & 0.9291 \\
& Patient bargaining power & $\sigma_{u}$ & 0.5329 \\
& Physician bargaining power & $\sigma_{w}$ & 1.0484 \\
The total variance of random items & $\sigma_{v}^{2}+\sigma_{u}^{2}+\sigma_{w}^{2}$ & 2.2465 \\
Variance Analysis & Overall effect of Asymmetric information & $\left(\sigma_{u}^{2}+\sigma_{w}^{2}\right) /\left(\sigma_{v}^{2}+\sigma_{u}^{2}+\sigma_{w}^{2}\right)$ & $61.57 \%$ \\
& Patient bargaining influence & $\sigma_{u}^{2} /\left(\sigma_{u}^{2}+\sigma_{w}^{2}\right)$ & $20.53 \%$ \\
& Physician bargaining influence & $\sigma_{w}^{2} /\left(\sigma_{u}^{2}+\sigma_{w}^{2}\right)$ & $79.47 \%$ \\
& Net effect of bargaining & $\sigma_{w}-\sigma_{u}$ & $51.55 \%$ \\
\hline
\end{tabular}

corresponding estimated equations are (10) and (11), which mean the percentage change of the surplus extracted by physicians and patients in the bargaining process relative to the benchmark $\log$ price estimated from $\ln \hat{P}=x_{i}^{\prime} \hat{\beta}$. Table 5 shows that on average, surplus extracted by physicians can increase the medical price by $51.28 \%$, while surplus extracted by patients can only decrease medical price by $34.76 \%$. These two opposite effects led to an increase in medical prices by $16.52 \%$ relative to benchmark price of medical services. In other words, due to the existence of information asymmetry and the difference in bargaining power between physicians and patients, patients need to spend $\$ 116.52$ for the $\$ 100$ medical service in a fair market.

The last three columns in Table 5 (Q1-Q3) show that differences in bargaining power between physicians and patients are highly heterogeneous, and almost all patients are at a disadvantage in the bargaining process. More specifically, the first quartile value of net surplus is $8.96 \%$, which means medical prices are only $8.96 \%$ above the benchmark price for $25 \%$ of the sample. The top $25 \%$ of the surplus extractions are more than $34 \%$, which increases about $18 \%$ relative to the average price.

\subsubsection{The Annual Results of the Sample Estimates}

Since the reform and opening-up in 1978, along with the promotion of economic system reform in various fields, China's medical service system reform has also developed in depth. To explore whether the degree of information asymmetry between physicians and patients will decrease with the progress of medical reform, I analyze the impact of bargaining on medical prices across different years. The results are reported in Table 6.

Unlike the results of Hongyou Lu et al. (2011) and Wei Xu et al. (2013), which show that the net surplus between physicians and patients barely changes over time [18] [19], Table 6 indicates that the net surplus changes corresponding to each reform. Especially, early waves of reforms rendered significantly high efficiency compared to later waves. I think the main reason for the difference in empirical results is that although the survey data we use involves different years, the data is not panel data, but mixed cross-section data. Namely, patients in each 
Table 5. Surplus extracted by patients and physicians.

\begin{tabular}{|c|c|c|c|c|c|}
\hline & Mean $(\%)$ & Standard deviation (\%) & Q1 (\%) & Q2 (\%) & Q3 (\%) \\
\hline Physicians: $\hat{E}\left(1-\mathrm{e}^{-w} \mid \varepsilon\right)$ & 51.28 & 18.25 & 36.78 & 46.44 & 62.07 \\
\hline Patients: $\hat{E}\left(1-\mathrm{e}^{-u} \mid \varepsilon\right)$ & 34.76 & 9.59 & 27.82 & 31.82 & 38.54 \\
\hline Net surplus: $\hat{E}\left(\mathrm{e}^{-u}-\mathrm{e}^{-w} \mid \varepsilon\right)$ & 16.52 & 26.16 & 8.96 & 14.62 & 34.25 \\
\hline
\end{tabular}

Table 6. Surplus extracted by patients and physicians across years.

\begin{tabular}{cccccc}
\hline Year & Mean (\%) & Standard deviation (\%) & Q1 (\%) & Q2 (\%) & Q3 (\%) \\
\hline 1991 & -6.54 & 38.62 & -33.78 & 0.00 & 18.32 \\
1993 & 13.90 & 39.01 & -13.73 & 16.44 & 49.34 \\
1997 & 15.66 & 38.00 & -13.55 & 14.25 & 51.68 \\
2000 & 9.60 & 39.61 & -22.94 & 9.51 & 45.91 \\
2004 & 18.24 & 30.29 & -2.48 & 17.75 & 41.68 \\
2006 & 24.90 & 24.78 & 6.80 & 21.13 & 41.58 \\
\hline
\end{tabular}

year are not coherent, because the data is not a follow-up survey, although the number of patients per year may be the same. And I believe that Hongyou Lu et al. (2011) and Wei Xu et al. (2013) are likely to assume that the parameters of the model do not change over time, and then put all the observations together to estimate. So, they concluded that the net surplus has hardly changed over time. However, I estimate separately in each year. Of course, to make the number of observations larger, we can also use the rolling estimation method after mixing two or three years of data, to better evaluate the degree of asymmetry information between physicians and patients.

Table 6 suggests that in 1991 patients' bargaining power was stronger than physicians', thus, patients can lower their medical expenditures by $6.54 \%$ relative to benchmark prices. This time corresponds to the second stage of China's medical reform (1985-1991): the official launch of a comprehensive medical reform. With the gradual reduction of government direct investment, the marketization of medical institutions has further strengthened the supply of medical and health services, thereby making full use of the "vote-by-foot" effects of patients and enhancing their bargaining power.

However, with the continuous progress of the third stage (1992-1999): marketization of medical institutions, government finances have been gradually withdrawn from the supply side, and the contract responsibility system has been introduced to hospitals. As a result, hospitals have become self-financing agencies. Nevertheless, even though the market-oriented profit-seeking behavior of medical institutions has greatly remedied the problem of insufficient income of medical and health institutions, it has also led to an unreasonable increase in medical prices coupled with the poor attitude of some medical staff. Therefore, to a cer- 
tain extent, the public welfare of medical institutions and the interests of the people have been harmed. Corresponding to Table 6, physicians always have stronger bargaining power than patients in 1993 and 1997, and the difference in bargaining power was increasing from1993 to 1997.

In 2000 , the auction of a total of more than 100 public hospitals achieved the exit of state-owned assets and the injection of private capital. Yet, it can be seen from Table 6 that, although the difference in bargaining power between physicians and patients has been reduced in 2000, the physician's bargaining power has always been stronger from 2000 to 2006 than the patient's, and compared to 1993, the net surplus extracted by physicians has increased over years. I believe there are two main reasons for this phenomenon. The first reason is that these profit-seeking medical institutions formed during the market-oriented reform stage have been further strengthened and gradually transformed into vested interest groups, which have exacerbated the existence of unscrupulous profiteering in the medical market. The second reason is that since the formal establishment of the medical insurance system combined social planning and individual accounts in 1997, the focus of China's medical reform has shifted from the supply-side to the demand-side. The establishment of the medical insurance system seems to be a process of introducing market mechanism into the demand side, increasing the proportion of demanders' payment for medical expenses, thereby restricting the excessive demand of demanders for medical services, and further withdrawing government finances from the demand side. At this stage, the demand side of medical markets has been weakened since the transfer and release of the responsibility that was originally borne by the government at the second stage. Consequently, contradictions in the medical market have been further aggravated.

To wrap up, since the reform and opening-up, the basic experience of China's medical and health system reform shows the government-run public medical service is not feasible due to its high cost. From another perspective, the competition mechanism can be introduced to the medical service market by opening medical markets, encouraging the development of private medical service institutions and reforming hospital property rights. And, to a certain extent, the introduction of competition mechanism can ease the pressure of government fiscal expenditure and promote the quantity and quality of medical and health services greatly. Moreover, the above empirical analysis shows that in the early stage, the market-oriented reform of medical institutions can indeed reduce the degree of information asymmetry between physicians and patients and has a positive impact on the efficiency of the medical market. However, under the dual pressures of income-generating assessment and money temptation, profit-seeking is a systematic behavior of the medical system. Public hospitals will gradually act like profit-oriented enterprises. Namely, they will take advantage of their asymmetrical information in medical field relative to patients, resulting in rapid and unreasonable growth in patients' medical expenditures. 


\section{Path Selection of China's New Round of Medical Reform}

\subsection{The Respective Roles of the Government and the Market in Medical Reform}

From the characteristics of medical service itself and the experience of medical reform in China since the reform and opening-up in 1978, I believe that the direction of China's new round of medical reform not only should insist on government-led efforts, but also should introduce market mechanisms. The scope of China's health reform can be divided into four segments: public health, medical services, pharmaceutical production and circulation, and medical insurance. In different fields, the respective roles of the government and the market should be different. In fact, the duty of the government and the market in the medical reform has been brilliantly exposed in Adam Smith's “The Wealth of Nations"- "The third and last duty of the sovereign or commonwealth is that of erecting and maintaining those public institutions and those public works, which, though they may be in the highest degree advantageous to a great society, are, however, of such a nature that the profit could never repay the expense to any individual or small number of individuals, and which it therefore cannot be expected that any individual or small number of individuals should erect or maintain. The performance of this duty requires, too, very different degrees of expense in the different periods of society" [57]. Consequently, from the viewpoint of modern market economy, the government should focus on weak parts of medical reform and let market itself regulate strong parts. Only in this way, can respective comparative advantages of social forces and governments be fully utilized. Therefore, I suggest that the responsibilities of the government and the market in the medical reform should be divided as follows (Table 7).

Specifically, in the field of public health services (including establishing health records, women's health care, elderly health care, vaccination, and health education, etc.), the government should shoulder its primary responsibility and shift the emphasis from treatment to prevention. In the field of medical services, a mixed system should be adopted. The government is mainly responsible for financing the establishment of non-profit medical institutions, and let the market regulate those for-profit ones. In the field of drug production and distribution, the circulation and pricing of medicines should mainly be decided by the market,

Table 7. The division of responsibilities between the government and the market.

\begin{tabular}{|c|c|c|c|c|c|c|}
\hline & \multirow{2}{*}{ Public Health } & \multicolumn{2}{|c|}{ Medical Services } & \multicolumn{2}{|c|}{$\begin{array}{c}\text { Pharmaceutical Production and } \\
\text { Circulation }\end{array}$} & \multirow{2}{*}{$\begin{array}{l}\text { Medical Insurance } \\
\text { (can be divided into } \\
\text { different levels) }\end{array}$} \\
\hline & & $\begin{array}{l}\text { For-profit } \\
\text { Hospitals }\end{array}$ & $\begin{array}{l}\text { Non-profit } \\
\text { Hospitals }\end{array}$ & $\begin{array}{l}\text { Price and } \\
\text { Circulation }\end{array}$ & $\begin{array}{l}\text { Quality } \\
\text { Standards }\end{array}$ & \\
\hline Government & $\sqrt{ }$ & & $\sqrt{ }$ & & $\sqrt{ }$ & $\sqrt{ }$ \\
\hline Market & & $\sqrt{ }$ & & $\sqrt{ }$ & & $\begin{array}{l}\sqrt{ } \text { (including personal } \\
\text { responsibilities) }\end{array}$ \\
\hline
\end{tabular}


while the government mainly supervises the quality standards of medicines. Medical insurance should be divided into different levels, then respectively shared by the government, market and individuals.

\subsection{Establish and Improve the General Practitioner System to Reduce the Asymmetry of Physician-Patient Information}

Given the important role of information asymmetry in the pricing process of medical services, and the fact that physicians have more information and more bargaining power than patients, there is a growing literature that studies how changing provider incentives can help overcome information asymmetry and reduce provider incentives to induce demand. At present, the common payment mechanism can be divided into retrospective payment system and prospective payment system. The retrospective payment system pays after the medical service is completed, and the "fee for service" (FFS, also known as "pay-for-performance") is the most commonly used one. Yet, due to the large amount of verification work required, it is inevitable that the quantity and quality of verification will be reduced, and ultimately this payment mechanism cannot effectively restrain excessive medical treatment. The prospective payment system, as the name suggests, pays before the medical service occurs, and the hospital "pays for overspending and obtains the surplus" [58]. Prospective payment methods include per capita payment (or capitation), global budget, per diem payment, case-based payment, and diagnosis-related groups (DRGs) et al. Although prospective payment system is a more cost-constrained method than retrospective payment system, driven by cost savings, prospective payment may encourage providers to lower the quality of medical services or reduce the necessary treatments, resulting in under-service to obtain more surplus. Therefore, in reality, the existence of information asymmetry and the inherent needs of medical service providers to maximize their utility, cut off the possible existence of ideal payment method (which can provide appropriate incentives for medical service providers, and allow them to consciously carry out cost control and quality assurance, and avoid the possibility of overdose or shortage of medical services [59]) [60]. Consequently, I believe that the establishment of a general practitioner system (which not only undertakes community primary health care services, but also differentiates the specialist medical and general medical services markets by determining whether patients need referral treatments) can increase the amount of information of patients, thus effectively improve the bargaining power of patients and efficiently lower the degree of information asymmetry between physicians and patients due to the following two reasons.

First, general practitioners are the gatekeepers of the health of residents. As they can provide a wide range of services including family nutrition guidance, disease prevention, disease treatment, child and elderly health care, and medical consultation and so on, general practitioners can greatly enhance the public's ability to prevent diseases and shift the focus from new treatments to disease prevention, thereby reducing the incidence of major diseases. In addition, since 
general practitioners get closer to patients, understand patients and are familiar with the medical characteristics and medical environment of various hospitals, the degree of information asymmetry between physicians and patients can be reduced more thoroughly.

Second, general practitioners are also the gatekeepers of the health care system. General practitioners provide residents with the first medical diagnosis, and then decide whether they need to be referred to higher-level hospitals according to the severity of their illness. And patients who have passed their serious phase in a referral hospital will be referred to the community hospital for further treatment or rehabilitation. Through primary diagnosis in communities and hierarchical referral system, the general practitioner system can improve the efficiency of physicians' diagnosis and treatment. Additionally, by extending the medical resources to the grassroots level, the general practitioner system can also change the present situation that medical resources are currently too concentrated in large cities and major hospitals and then optimize the allocation of medical and health resources to help solve the problem of expensive medical bills and limited access to quality medical services. In 2011, the State Council of China decided to establish a general practitioner system and promulgated "The Guiding Opinions on Establishing a General Practitioner System", which not only has made a prospective and directive design for the training, practicing and incentive systems of general practitioners, but also is a milestone in the development of General Practice in China. However, the general practitioner system in China started late and was not yet mature. Therefore, with reference to the experiences of foreign general practitioner systems, China should seize the opportunity of the new round of medical reform and accelerate the improvement of the system of general practitioners.

\section{Conclusion}

In this paper, I use a two-tier stochastic frontier model to analyze the impact of asymmetric information between physicians and patients on the final medical service expenditures both holistically and annually, based on the China Health and Nutrition Survey (CHNS) data and the development of China's medical and health system reform since 1978. The empirical results show that: 1) Despite the strong heterogeneity in the bargaining power between physicians and patients, on average, the net effect leads to an increase in actual medical service expenses by $16.52 \%$ relative to benchmark prices. 2) The series of medical reforms in China had different impacts on medical care pricing efficiency. Especially, the early wave of reforms could have a positive impact on the efficiency of the medical market at an early stage. The above empirical analysis indicates that relying solely on government-led or market-oriented medical system reform cannot improve the efficiency of China's medical market in the long run. Therefore, China's medical reform must combine government-led efforts and market economy, so that not only the public welfare of medical services can be guaran- 
teed, but medical efficiency can be improved as well. According to the above empirical analysis, this paper further provides recommendations on the division of responsibilities between the government and the market in the new round of China's medical reform and how to reduce the information asymmetry between physicians and patients.

\section{Conflicts of Interest}

The author declares no conflicts of interest regarding the publication of this paper.

\section{References}

[1] Li, X. (2018) China Doctor-Patient Relationship. Investigation Report-Analysis of Doctor-Patient Relationship. Contemporary Medicine, 24, 183-186.

[2] Li, L. (2004) Foreign Medical and Health System and Its Enlightenment to China's Medical and Health Care Reform. Red Flag Document, No. 21, 18-21.

[3] Li, L. (2006) China's Medical System Reform Trend. Red Flag Document, No. 10, 19-21.

[4] Gu, X., Gao, M.T. and Yao, Y. (2006) Diagnosis and Prescription-Facing the Reform of China's Medical System. Social Sciences Academic Press, Beijing.

[5] Liu, G.G. and Zhan, C.H. (2006) Do Not Misread the "Government-Led". Chinese Health, No. 9, 24-26.

[6] Wang, H.F. (2010) The Role of Government and Market Should Both Be Played in China's Medical Reform. China Medical Insurance, No. 6, 34.

[7] Zhou, S.L. (2011) Fairness Enforced by the Government and Efficiency Promoted by Market-Pathway to Medical Reform Following the Rule of Socialist Market Economy. The Chinese Health Service Management, 28, 484-485.

[8] Akin, J.S., Griffin, C.C., Guilkey, D.K. and Popkin, B.M. (1986) The Demand for Primary Health Care Services in the Bicol Region of the Philippines. Economic Development and Cultural Change, 34, 755-782. https://doi.org/10.1086/451558

[9] Hansen, K.K. and Zwanziger, J. (1996) Marginal Costs in General Acute Care Hospitals: A Comparison Among California, New York and Canada. Health Economics, 5, 195-216. https://doi.org/10.1002/(SICI)1099-1050(199605)5:3<195::AID-HEC201>3.0.CO;2-Q

[10] Gupta, S., Verhoeven, M. and Tiongson, E.R. (2002) The Effectiveness of Government Spending on Education and Health Care in Developing and Transition Economies. European Journal of Political Economy, 18, 717-737. https://doi.org/10.1016/S0176-2680(02)00116-7

[11] Wang, Y., Gong, X.W. and Zhao, P. (2005). Information Economics Explain of Excessive Growth of Medical Cost in China. Journal of Chongqing University, 28, 142-145.

[12] Wang, J., Chang, Z.Z. and Liu, H. (2008) Health Care Demand and Choice of Medical Treatment. Economic Research Journal, No. 7, 105-117.

[13] Gauthier, B. and Wane, W. (2011) Bypassing Health Providers: The Quest for Better Price and Quality of Health Care in Chad. Social Science and Medicine, 73, 540-549. https://doi.org/10.1016/j.socscimed.2011.06.008

[14] Huang, Y.X., Ye, Y.R. and Hu, Z.L. (2003) Analysis of the Competitive Situation of 
China's Medical Service Market in the Next Ten Years. International Medicine and Health Guidance News, No. 7, 63-65.

[15] Li, C.X., Wu, Z.C., Xu, L. and Gao, J. (2006) Gender Differences in Medical Expenditure in China. Chinese Health Economics, 25, 46-48.

[16] Zong, L., Wen, X.N. and Gao, B. (2006) Research on Prediction of Medical Expenses in China. Statistics and Decision, No. 5, 71-72.

[17] Phelps, C.E. (1992) Diffusion of Information in Medical Care. Journal of Economic Perspectives, 6, 23-42. https://doi.org/10.1257/jep.6.3.23

[18] Lu, H.Y., Lian, Y.J. and Lu, S.F. (2011) Measurement of the Information Asymmetric in Medical Service Market of China. Economic Research Journal, No. 4, 94-106.

[19] Xu, W., Ding, Y.L. and Liu, Y. (2013) Measurement about Information Asymmetry Degree of Chinese Medical Service Market. Computer Modelling and New Technologies, 17, 277-288.

[20] Wang, S.G. and Lei, H. (2017) Measurement of Medical Bargaining Power of the Elderly Population in China. Scientific Research on Aging, 5, 35-45.

[21] Phelps, C.E. (1997) Health Economics. Addison-Wesley Educational Publishers Inc., New York, NY.

[22] Yang, X.X. (2013) The Economic Characteristics and Reform Path Selection of Medical Services. Commercial Times, No. 23, 106-107.

[23] Hadley, J., Holahan, J. and Scanlon, W. (1979) Can Fee-For-Service Reimbursement Coexist with Demand Creation? Inquiry, 16, 247-258.

[24] Feldstein, M.S. (1970) The Rising Price of Physician's Services. Review of Economics and Statistics, 52, 121-133. https://doi.org/10.2307/1926113

[25] Rice, T.H. (1983) The Impact of Changing Medicare Reimbursement Rates on Physician-Induced Demand. Medical Care, 21, 803-815.

https://doi.org/10.1097/00005650-198308000-00004

[26] Yip, W.C. (1998) Physician Response to Medicare Fee Reductions: Changes in the Volume of Coronary Artery Bypass Graft (CABG) Surgeries in the Medicare and Private Sectors. Journal of Health Economics, 17, 675-699. https://doi.org/10.1016/S0167-6296(98)00024-1

[27] Zhu, H.P. (2007) Abuses in the Health Care System and Distortions in Pharmaceutical Pricing. Chinese Social Science, No. 4, 89-103.

[28] Gao, C.L., Mao, F.F. and Yu, H. (2009) Incentive Mechanism, Financial Burden and Evolution of China's Medicare System-Based on Interpretation of Relevant Documents of Medical System after the Founding of China. Management World, No. 4, 66-74.

[29] Gu, X. (2011) The Failure of Price Control and the High Price of Medicine in Public Hospitals. Governance Studies, 27, 12-22.

[30] Du, C. (2013) Price Control and Excessive Medical Care. The Journal of World Economy, 36, 116-140.

[31] Mommaerts, C. (2018) Are Coresidence and Nursing Homes Substitutes? Evidence from Medicaid Spend-Down Provisions. Journal of Health Economics, 59, 125-138. https://doi.org/10.1016/j.jhealeco.2018.04.003

[32] Gong, X.W., Wang, Y. and Li, T.Y. (2004) Game of Hospital-Patient Relationship under Asymmetric Information. Journal of Chongqing University, 27, 126-129.

[33] Xu, Z.D. and Zang, L.L. (2002) The Influence of Medical Service Information Publicity System on Hospitals and Its Countermeasures. Chinese Journal of Hospital 
Administration, 18, 183-184.

[34] Du, X.N., Wang, X.J., Xu, Z. and Heng, Y.L. (2016) Using Micro-Media to Improve the Asymmetry of Doctor-Patient Information. Health Management in Jiangsu, 27, 153-154.

[35] Satterthwaite, M. (1979) Consumer Information, Equilibrium Industry Price, and the Number of Sellers. The Bell Journal of Economics, 10, 483-502. https://doi.org/10.2307/3003348

[36] Akin, J.S. and Hutchinson, P. (1999) Health-Care Facility Choice and the Phenomenon of Bypassing. Health Policy and Planning, 14, 135-151. https://doi.org/10.1093/heapol/14.2.135

[37] Leonard, K.L., Mliga, G.R. and Mariam, D.H. (2002) Bypassing Health Centers in Tanzania: Revealed Preferences for Quality. Journal of African Economies, 11, 441-471. https://doi.org/10.1093/jae/11.4.441

[38] Sun, Q.X., Zhu, J.S., Zheng, W. and Li, M.Q. (2007) Reform of China's Medical Insurance System: The Three Pillar Framework for Universal Health Insurance. Economic Science, No. 5, 8-17.

[39] Liu, H.L., He, S.H., Xiao, J.H., Zeng, L.B. and Chen, Q. (2013) Research on the Reform of Payment Methods of Social Medical Insurance Suppliers in China under the Background of New Medical Reform. Labor Security World, No. 2, 32-34.

[40] Ding, J.H. and Zhu, M.L. (2004) Discussion on the Reform of Medical Insurance System and Effective Control of Medical Expenses Growth in China. Nankai Economic Studies, No. 4, 96-99.

[41] Wang, Z.F. (2011) The Definition of Medical Insurance Negotiation Mechanism. China Social Security, No. 4, 80-82.

[42] Zhong, Y.M. (2011) The Basic Course and Evaluation of China's Medical Reform Decision Since 1949. New Horizons from Tian Fu, No. 4, 96-100.

[43] Lian, Y.J. and Chung, C.F. (2008) Are Chinese Listed Firms Over-Investing? Social Science Electronic Publishing, Rochester, NY.

[44] Huang, S.W., Jia, J. and Wang, W.J. (2017) Research of IPO Underpricing Decomposition Based on Two-tiered Stochastic Frontier Model: Evidence from Chinese Growth Enterprises Market. Chinese Journal of Management Science, 25, 21-29.

[45] Tan, Y. and Shen, J.A. (2015) Measurement of the Bargaining Ability of CPA Firms and Issuers in IPOs: Based on Bilateral Random Boundary Model. Finance and Accounting Monthly, No. 36, 86-91.

[46] Kumbhakar, S.C. and Parmeter, C.F. (2010) Estimation of Hedonic Price Functions with Incomplete Information. Empirical Economics, 39, 1-25. https://doi.org/10.1007/s00181-009-0292-8

[47] Shinya, K. and Kazuyuki, M. (2010) Bargaining in Technology Markets: An Empirical Study of Biotechnology Alliances. Discussion Papers, 39.

[48] Ferona, A. and Tsionas, E.G. (2012) Measurement of Excess Bidding in Auctions. Economics Letters, 116, 377-380. https://doi.org/10.1016/j.econlet.2012.04.025

[49] Kumbhakar, S.C. and Parmeter, C.F. (2009) The Effects of Match Uncertainty and Bargaining on Labor Market Outcomes: Evidence from Firm and Worker Specific Estimates. Journal of Productivity Analysis, 31, 1-14. https://doi.org/10.1007/s11123-008-0117-3

[50] Gaynor, M. and Polachek, S.W. (1994) Measuring Information in the Market: An Application to Physician Services. Southern Economic Journal, 60, 815-831. 
https://doi.org/10.2307/1060422

[51] Chawla, M. (2002) Estimating the Extent of Patient Ignorance of the Health Care Market. In: Devarajan, S. and Rogers, F.H., Eds., World Bank Economists' Forum, Vol. 2, World Bank Publications, Washington DC, 3-24.

[52] Tomini, S. and Pavlova, M. (2012) Paying Informally in the Albanian Health Care Sector: A Two-Tiered Stochastic Frontier Model. European Journal of Health Economics, 13, 777-788. https://doi.org/10.1007/s10198-011-0331-1

[53] Osbourne, M.J. and Rubinstein, A. (1990) Bargaining and Markets (Chapter 5). Academic Press, San Diego.

[54] Kumbhakar, S.C. and Lovell, C.A.K. (2000) Stochastic Frontier Analysis. Cambridge University Press, New York, 90. https://doi.org/10.1017/CBO9781139174411

[55] Polachek, S.W. and Yoon, B.J. (1987) A Two-Tiered Earnings Frontier Estimation of Employer and Employee Information in the Labor Market. Review of Economics and Statistics, 69, 296-302. https://doi.org/10.2307/1927237

[56] Polachek, S.W. and Yoon, B.J. (1996) Panel Estimates of a Two-Tiered Earnings Frontier. Journal of Applied Econometrics, 11, 169-178. https://doi.org/10.1002/(SICI)1099-1255(199603)11:2<169::AID-JAE373>3.0.CO;2-\#

[57] Sutherland, K., Norlen, P., Masutani, K., Fleecs, T., Bromwich, D. and Mungello, D. (2016) An Inquiry into the Nature and Causes of the Wealth of Nations: A Selected Edition (Oxford World's Classics).

[58] Gu, X. (2012) Towards a Public Contract Model: The Strategic Significance of Provider-Payment Reforms to China's New Healthcare Reforms. Comparative Economic and Social Systems, No. 4, 21-31.

[59] Duran, A., Sheiman, I., Schneider, M. and Øvretveit, J. (2005) Purchasers, Providers and Contracts. In: Figueras, J., Robinson, R. and Jakubowski, E., Eds., Purchasing to Improve Health Systems Performance, Open University Press, Maidenhead, UK, 187-214.

[60] Guo, K. and Gu, X. (2017) Dealing with the Issue of Supplier-Induced Over-Consumption: Price Regulation, Competition, or Provider-Payment Reforms? Social Sciences in Guangdong, No. 5, 176-185. 